\title{
Zeolite-templated NiO Nanostructure for Methanol Oxidation Reaction
}

\author{
DAIFALLAH M. ALDHAYAN \\ Department of Chemistry, Faculty of Science, King Saud University, Riyadh, Kingdom of Saudi Arabia. \\ ${ }^{*}$ Corresponding author E-mail: aldhayan@ksu.edu.sa \\ http://dx.doi.org/10.13005/ojc/340549
}

(Received: August 23, 2018; Accepted: September 10, 2018)

\begin{abstract}
Nickel oxide nano with particle size of 10.0 to $15.0 \mathrm{~nm}$ using zeolite as a template were successfully prepared and loaded (NiO $10 \mathrm{wt} . \%)$ on functionalized carbon nanofibers (CNFs). The as-prepared material NiO-CNFs was characterized and tested as an electrocatalyst and a catalyst for the methanol conversion. Electrocatalytic results showed high stability which was evinced by repetitive cycles as a result of catalyst surface activation. Gas phase catalytic tests were carried out at $290^{\circ} \mathrm{C}$ over NiO-CNFs catalyst in fresh, reduced, and oxidized forms. The results showed that dimethyl ether (DME) and $\mathrm{CO}_{2}$ were obtained as main products. Formaldehyde (FA), Methyl formate (MF) and Dimethoxymethane (DMM) were obtained as traces. The conversion of methanol in the absence of $\mathrm{H}_{2}$ or $\mathrm{O}_{2}$ over inactivated NiO-CNFs catalyst suggested that DME reacts with the formed $\mathrm{H}_{2} \mathrm{O}$ to produce $\mathrm{CO}_{2}$. In both cases, reactivation of the catalyst by $\mathrm{H}_{2}$ (reduction) or by Air (oxidation), the conversion was increased indicating a regeneration of the catalyst.
\end{abstract}

Keywords: Zeolite, Electrocatalyst, NiO nanoparticles, Microporous, Template, Methanol oxidation, Fuel cell.

\section{INTRODUCTION}

Porous solids are categorized in three classes: Microporous materials with a pore diameter $(<2 \mathrm{~nm})$, mesoporous materials are materials with a pore diameter of 2-50 $\mathrm{nm}$ and macroporous materials with a pore diameter $(>50 \mathrm{~nm})^{1,2}$. Mesoporous materials have attracted high interest due to their unique properties such as large surface area, uniform pore size and pore size distribution which makes them suitable for many applications such as energy conversion ${ }^{3}$, Sensors ${ }^{4}$, Catalysis ${ }^{5}$ and bio-related applications ${ }^{6}$. They are also used as templates for making molecular sieves, sensors and synthesis of controlled size nanoparticles ${ }^{2}$. On the other hand, microporous materials such as zeolite are known for many applications such as catalysis, and sorption due to their high stability and selectivity ${ }^{7}$. It has been reported that zeolite can be used as a starting materials to produce mesoporous structures through desiccation process by alkaline treatment of zeolite ${ }^{7,8}$. Here we report the syntheses of Nickel oxide nanoparticles using zeolite ZSM- 5 to produce mesoporous structure and then the removal of the zeolite by the alkali treatment. Prepared NiO Nanoparticles has been supported on carbon fibers 
to be used as electrocatalyst and a catalyst towards methanol conversion.

\section{MATERIALS AND METHODS}

\section{Zeolite Preparation and loading}

In a typical hydrothermal synthesis procedure $^{9}$, an exact amount of 3.4M NaOH solution was added to Pyramid sodium silicate $(29.25 \% \mathrm{wt}$ $\mathrm{SiO}_{2}, 8.85 \%$ wt $\mathrm{Na}_{2} \mathrm{O}, 61.9 \%$ wt $\mathrm{H}_{2} \mathrm{O}$ ) (Crossfield Chemicals) under stirring at room temperature, then a mixture solutions of sodium Aluminate $\mathrm{NaAlO}_{2}$ (52.3\% wt $\mathrm{Al}_{2} \mathrm{O}_{3}, 47.7 \%$ wt $\mathrm{Na}_{2} \mathrm{O}$ ) (BDH Chemicals) and Tetra Propyl Ammonium Hydroxide TPAOH (20\% aqueous solution) (Aldrich Chemicals Co) were added individually with vigorous stirring. The reaction kept under stirring for at least $2 \mathrm{~h}$ and then transferred into a $250 \mathrm{ml}$ Teflon-lined steel autoclave. Reaction kept at $170^{\circ} \mathrm{C}$ under pressure for 24 hours. The product was filtered, rinsed with deionized water, dried, and calcined at $540^{\circ} \mathrm{C}$ for $8 \mathrm{~h}$ to remove the template 10. A certain amount of the prepared ZSM-5 zeolites was then kept under vacuum at $150^{\circ} \mathrm{C}$ overnight, then added to a solution of $\mathrm{Ni}\left(\mathrm{NO}_{3}\right)_{2}$ and sonication for $4 \mathrm{~h}$ followed by vacuum drying. Zeolite sample loaded with Nickel salt was then calcined at $350^{\circ} \mathrm{C}$ for 2 hours. Zeolite template was removed using $1 \mathrm{M} \mathrm{NaOH}$ solution for $5 \mathrm{~h}$ at $80^{\circ} \mathrm{C}$ with stirring.

\section{Preparation of NiO/Carbon fiber nanocatalyst}

Carbon fibers support was prepared according to the method reported by Al-Enizi et. al., ${ }^{11}$. In a typical synthesis, polyacrylonitril elctrospin fibers were produced using electrospinning technique. Produced fibers were collected, dried then transferred to carbon fibers using pyrolysis process under Nitrogen atmosphere at $1100^{\circ} \mathrm{C}$ for 6 hours. The obtained $\mathrm{NiO}$ material was dried at $70^{\circ} \mathrm{C}$ overnight. To achieve 10 wt.\% loading of $\mathrm{NiO}$ on the Carbon fibers (CNFs), an appropriate amount of $\mathrm{NiO}$ and CNFs was mixed and sonicated in deionized water for 30 minutes.

\section{Materials characterization}

The $\mathrm{C}, \mathrm{H}$, and $\mathrm{N}$ contents of prepared $\mathrm{NiO} /$ Carbon fiber nanocatalyst were determined using PerkinEImer 2400 Series II CHNS/O elemental analyzer and for the characterization of crystal structure, Bruker D8 Advance x-ray diffractometer has been used. The TEM characterization of $\mathrm{NiO}$ nanoparticles was preform on Jeol high resolution transition electron microscope (HRTEM 2100) operated at $200 \mathrm{kV}$.

\section{Catalytic measurements}

Conversion of methanol was used to test the acid and redox properties of the catalyst. Oxidation tests were carried out at atmospheric pressure using a fixed-bed continuous-flow reactor. The catalyst (250 mg), packed in a stainless steel reactor, was preconditioned at $330^{\circ} \mathrm{C}$ under air flow for $2 \mathrm{~h}$ at a rate of $80 \mathrm{ml} / \mathrm{min}$. After the pre-treatment, the reagent mixture, which consisted of a mixture of methanol and air with volume ratio air $/ \mathrm{CH}_{3} \mathrm{OH}=2 / 0.5$, was admitted in the reactor (admission of methanol was carried out automatically and continuously by micro-injection through a syringe). The reaction was conducted at $250^{\circ} \mathrm{C}$. AS for reduction tests, the loaded catalyst sample was preconditioned at $330^{\circ} \mathrm{C}$ under $\mathrm{H}_{2}$ flow for $2 \mathrm{~h}$ at a rate of $80 \mathrm{ml} / \mathrm{min}$. After the pre-treatment, the reagent mixture, methanol and $\mathrm{H}_{2}\left(\mathrm{H}_{2} / \mathrm{CH}_{3} \mathrm{OH}=2 / 0.5\right)$, was admitted in the reactor. The reaction products were analyzed with a gas phase chromatograph (Agilent $6890 \mathrm{~N}$ ) equipped with a flame ionization detector and a capillary column (HP-PLOT Q length $30 \mathrm{~m} \mathrm{ID}$ $0.53 \mathrm{~mm}$ ).

\section{Electrocatalytic measurements}

Working electrodes were fabricated by dispersing $0.2 \mathrm{mg}$ of the prepared materials in a solution of $0.5 \mathrm{ml}$ isopropyl alcohol and $0.1 \mathrm{ml}$ Nafion (10 wt.\%) and sonicating the solution for $1 \mathrm{~h} \mathrm{Next,}$ $10 \mu \mathrm{l}$ of the dispersion was cast onto a glassy carbon (GC) disk electrode (GAMRY Instrument Company, $A=0.071 \mathrm{~cm}^{2}$ ) and left to dry overnight. Before inserting the electrode into the electrolytic cell, its surface was flushed with the same electrolyte that was used in the measurements in order to confirm the surface wettability ${ }^{11}$.

\section{RESULTS AND DISCUSSION}

The result of X-ray powder diffraction analysis of the calcined ZSM-5 zeolite is shown in Fig. 1. The sample exhibited the characteristic diffraction lines of the ZSM-5 framework characterized by the reflections in the 2 theta range of $7-9^{\circ}$ and 
23-25, which matched well with the standard pattern of ZSM-5 zeolite $^{12}$. The obtained XRD spectrum confirmed successful preparation of a highly crystalline ZSM-5, as indicated by the well resolved XRD peaks and the weak background noise in the XRD patterns.

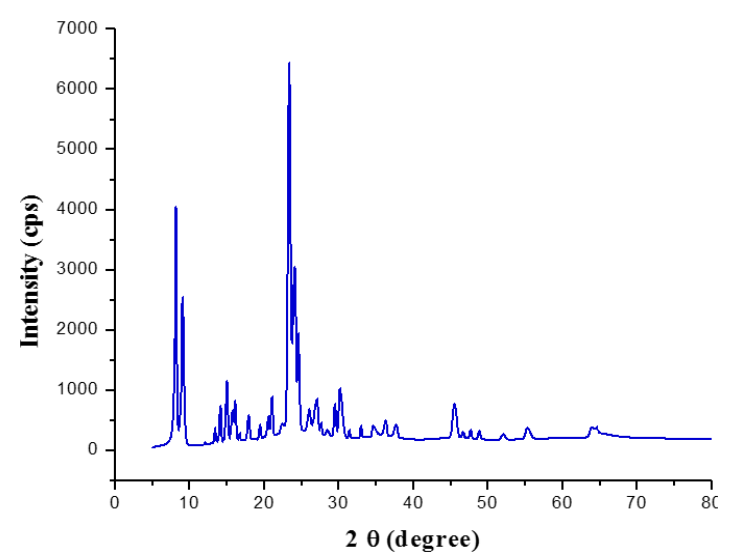

Fig. 1. XRD patterns of the ZSM- 5 calcined at $540{ }^{\circ} \mathrm{C}$ for 8 hours

TEM image after alkali treatment of zeolite template (Fig. 2), indicate the formations of uniform $\mathrm{NiO}$ particles of thickness about 3-6 $\mathrm{nm}$.

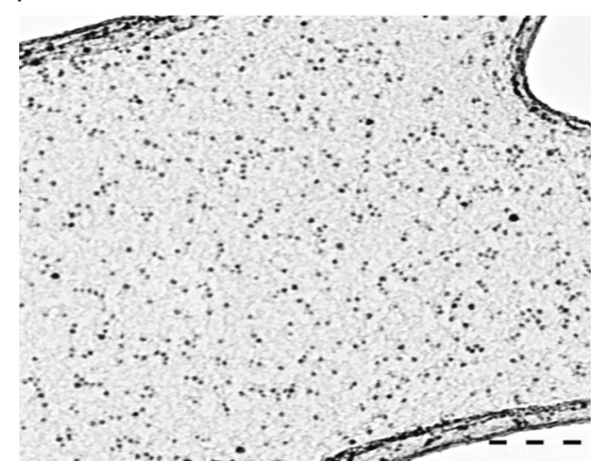

Fig. 2. TEM images of $\mathrm{NiO}$ nanoparticles

The XRD pattern of the prepared $\mathrm{NiO} / \mathrm{CNFs}$ electrocatalyst shows diffraction peaks at $2 \theta 37.3^{\circ}$, $43.3^{\circ}$, indexed to the (111) and (200) of cubic NiO phases respectively (Fig. 3$)^{13}$ and a diffraction peak at about $26^{\circ}$ which can be assigned to plane (002) of the hexagonal structure of the carbon nanofibers CNFs 10 . The other smaller XRD peaks at about $2 \theta$ $52^{\circ}$ and $77^{\circ}$ are assigned to (004) and (110) planes of the hexagonal structure of Graphite C $2 \mathrm{H}$ (ICDD 00-041-1487) respectively.

The prepared electrocatalyst with composition of $10 \% \mathrm{NiO} / \mathrm{CNF}$ s has been tested for the methanol oxidation reaction. The electrocatalytic activity has been recorded in Fig. 4, indicating the presence of methanol oxidation peak in the potential range between +1.1 to $+1.3 \mathrm{~V}$. On the other hand, Fig. 5 shows the effect of the scan rate on the peak current, indicating the increase of the peak current with increasing the scan rate. Stability proof of the Prepared electrocatalayst, can be assured by repetitive cycling between $+0.5 \mathrm{~V}$ and $+1.5 \mathrm{~V}$ in 0.5 $\mathrm{M} \mathrm{KOH}+1 \mathrm{M} \mathrm{MeOH}$ solution at temperature of $25^{\circ} \mathrm{C}$ and a scan rate of $50 \mathrm{mV} \mathrm{s}^{-1}$, results were depicted in Fig. 6. Fig. 6 shows that, the peak current density increased from $0.95 \mathrm{~mA} \mathrm{~cm}^{-2}$ in the 1 st cycle to 1.2 $\mathrm{mA} \mathrm{cm}^{-2}$ in the $20^{\text {th }}$ cycle as a result of catalyst surface activation by repetitive cycling. However, after $\mathrm{NaOH}$ treatment of the zeolite, the formation of nickel silicate cannot be excluded. This can be in partial, the reason for the high stability of the catalyst. Additional studies of both the intermediate $\mathrm{NiO}$ material and the final NiO-CNFs catalyst are needed.

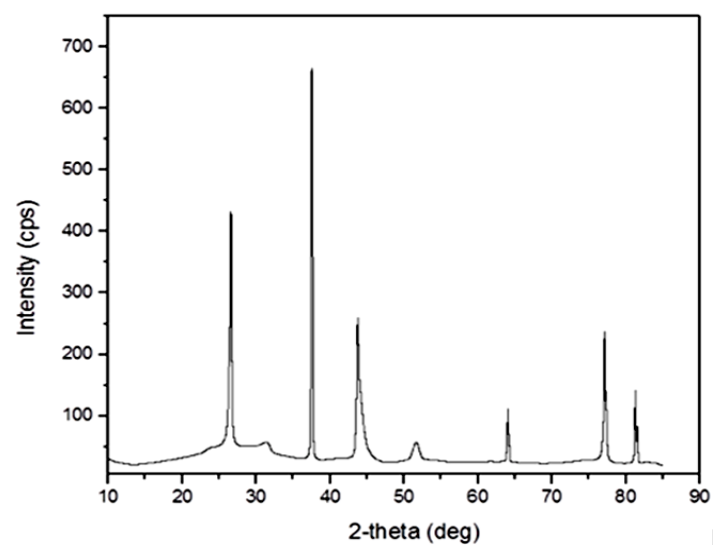

Fig. 3. XRD patterns of CNFs loaded with $10 \% \mathrm{NiO}$

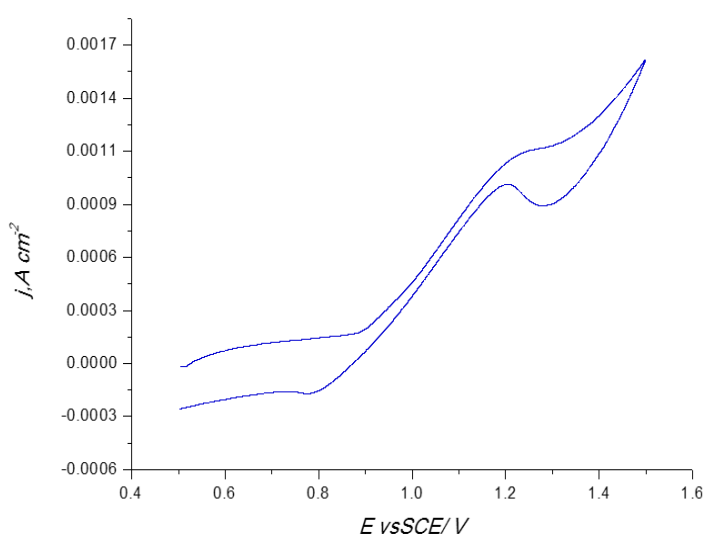

Fig. 4. CV $10 \% \mathrm{NiO} / \mathrm{CNF}$ in a solution of $0.5 \mathrm{M} \mathrm{KOH} / 1 \mathrm{M}$ $\mathrm{MeOH}$ at a scan rate of $50 \mathrm{mV} \mathrm{s}^{-1}$ 


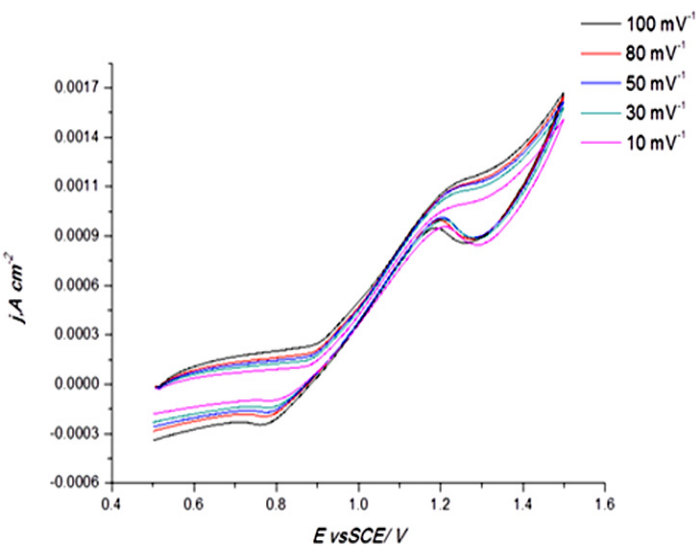

Fig. $5 . \mathrm{CV}$ for the $10 \% \mathrm{NiO} / \mathrm{CNF}$ in a solution of $0.5 \mathrm{M}$ $\mathrm{KOH} / 1 \mathrm{M} \mathrm{MeOH}$ at different scan rate

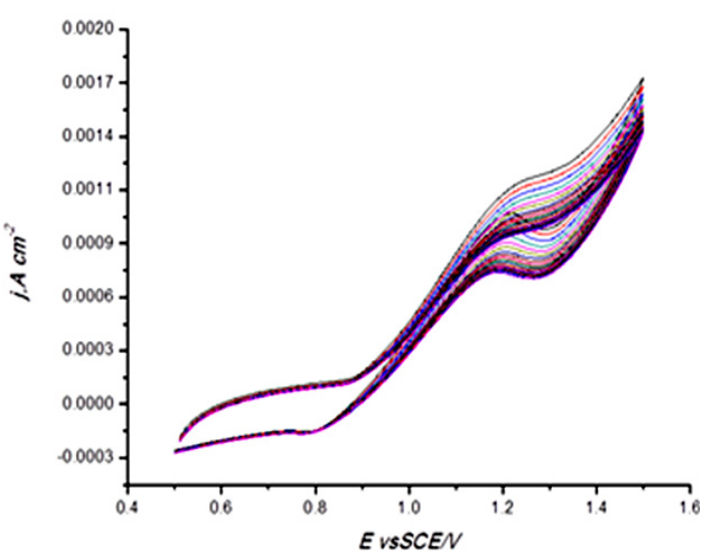

Fig. 6. Repetitive CVs for $10 \% \mathrm{NiO} / \mathrm{CNFs}$ in a solution of $0.5 \mathrm{M} \mathrm{M} \mathrm{KOH}+1 \mathrm{M} \mathrm{MeOH}$ at $25^{\circ} \mathrm{C}$ at a scan rate of $50 \mathrm{mV} \mathrm{s}^{-1}$

The reaction of methanol conversion is considered to be sensitive to the structure ${ }^{14}$, the dispersion ${ }^{15}$ and the interaction force between the active phase and the support ${ }^{16}$. For this reason it was selected as a reaction test to characterize the as-prepared catalyst. The reactions of conversion of methanol were carried out at $290^{\circ} \mathrm{C}$ and $250^{\circ} \mathrm{C}$ over the as-prepared catalyst. The results show that the reaction led to dimethyl ether (DME) and $\mathrm{CO}_{2}$ as main products while formaldehyde (FA), methyl formate (MF) and dimethoxymethane (DMM) were observed as traces.

DME can be produced by methanol dehydration:

$$
2 \mathrm{CH}_{3} \mathrm{OH} \rightarrow \mathrm{CH}_{3} \mathrm{OCH}_{3}+\mathrm{H}_{2} \mathrm{O}
$$

$\mathrm{CO}_{2}$ can be produced by methanol or by DME total oxidation
$\mathrm{CH}_{3} \mathrm{OH}+\mathrm{H}_{2} \mathrm{O} \rightarrow 3 \mathrm{H}_{2}+\mathrm{CO}_{2}$

$\mathrm{CH}_{3} \mathrm{OH}+1 / 2 \mathrm{O}_{2} \rightarrow 2 \mathrm{H}_{2}+\mathrm{CO}_{2}$

$\mathrm{CH}_{3} \mathrm{OH}_{3}+3 \mathrm{H}_{2} \mathrm{O} \rightarrow 6 \mathrm{H}_{2}+2 \mathrm{CO}_{2}$

$\mathrm{CH}_{3} \mathrm{OCH}_{3}+3 \mathrm{O}_{2} \mathrm{O} \rightarrow 2 \mathrm{CO}_{2}+3 \mathrm{H}_{2} \mathrm{O}$

The acid character of the catalyst is indicated by the amount of dimethyl ether (DME) formed, while the redox character is indicated by the formation of $\mathrm{CO}_{2}$. Besides $\mathrm{CO}_{2}$, the other reaction products such as $F A$, (FM) and DMM, which are formed by condensation of methanol and FA in consecutive reactions, also indicate the redox character of the catalyst.

The catalyst was tested initially, for the conversion of methanol at a reaction temperature of $290^{\circ} \mathrm{C}$ without being activated. The results Fig. 7 showed that the conversion increased as the reaction time increased from 0.5 to 2 hours. Beyond $2 \mathrm{~h}$ it decreased, indicating the deactivation of the catalyst. As for the variation of the selectivities with time on stream, it has been found that when the reaction time increases from 0,5 to $2 \mathrm{~h}$ the selectivity of the DME decreased in favor of $\mathrm{CO}_{2}$. The formation of the DME is due to the acidic sites $(\mathrm{OH})$ created during the functionalization (treatment with $\mathrm{H}_{2} \mathrm{SO}_{4}$ ) of the CNFs support. In fact, the treatment with $\mathrm{H}_{2} \mathrm{SO}_{4}$ leads to the creation of oxygenated groups (Acid sites and redox) such as $\mathrm{COOH}, \mathrm{C}=\mathrm{O}$ and $\mathrm{OH}$. Then, the DME form is oxidized by the redox sites of the support and $\mathrm{NiO}$ leading to the formation of $\mathrm{CO}_{2}$. These results are in agreement with those reported in the literature ${ }^{17}$ where it was mentioned that methanol leads to DME which reacts with $\mathrm{H}_{2} \mathrm{O}$ to produce $\mathrm{CO}_{2}\left(\mathrm{CH}_{3} \mathrm{OCH}_{3}\right.$ $\left.+3 \mathrm{H}_{2} \mathrm{O} \rightarrow 6 \mathrm{H}_{2}+{ }_{2} \mathrm{CO}_{2}\right)^{18}$. $\mathrm{CO}_{2}$ is also formed by reactions of methanol with $\mathrm{H}_{2} \mathrm{O}^{19}$.

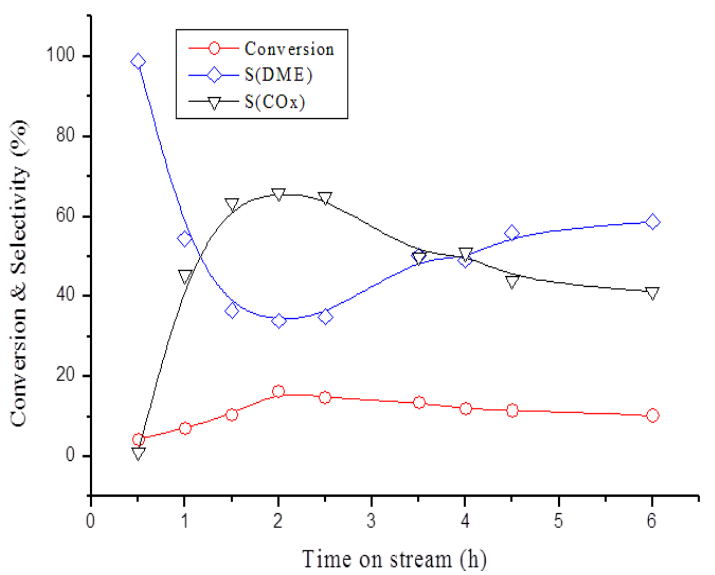

Fig. 7. Dependence of the conversion and product selectivities on time on stream reaction over $\mathrm{NiO} / \mathrm{CNFs}$, at $290^{\circ} \mathrm{C}$ 
The sample that was tested for the reaction of methanol alone at $290^{\circ} \mathrm{C}$ was activated by $\mathrm{H}_{2}$ and tested for the $\mathrm{CH}_{3} \mathrm{OH} / \mathrm{H}_{2}$ reaction, then after it was activated by air, it was tested for the $\mathrm{CH}_{3} \mathrm{OH}$ / Air reaction at the same reaction temperature. The change of the conversion and the selectivities with time on stream are shown in Fig. 8 and 9 respectively. It can be seen that in both cases the conversion increased with temperature and reached a value higher than that obtained for the reaction of methanol alone. As for the selectivities, it can be seen that $\mathrm{H}_{2}$ increased the selectivity of DME to the detriment of that of $\mathrm{CO}_{2}$, whereas air $\left(\mathrm{O}_{2}\right)$ decreased DME selectivity in favor of that of $\mathrm{CO}_{2}$. These results can be explained by the fact that $\mathrm{H}_{2}$ shifts the equilibrium of the conversion of DME to the left (equation 4) and thus decreased the conversion of DME into $\mathrm{CO}_{2}$. On the other hand, $\mathrm{O}_{2}$ increased the conversion of methanol and DME to $\mathrm{CO}_{2}$.

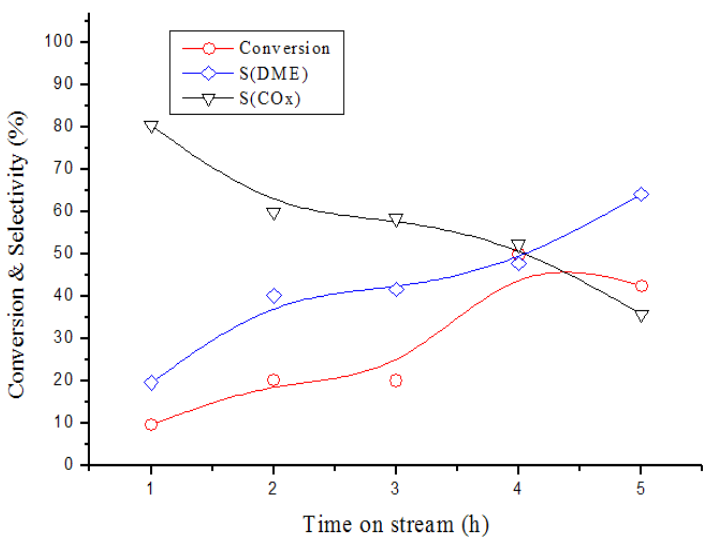

Fig. 8. Dependence of the conversion and product selectivities on time on stream reaction over NiO/CNFs. Reaction conditions: reaction temperature $290^{\circ} \mathrm{C}$; activation temperature $330^{\circ} \mathrm{C}$ for $2 \mathrm{~h}$ under $\mathrm{H}_{2}$; volume ratio $\mathrm{H}_{2} / \mathrm{CH}_{3} \mathrm{OH}=2 / 0.5$

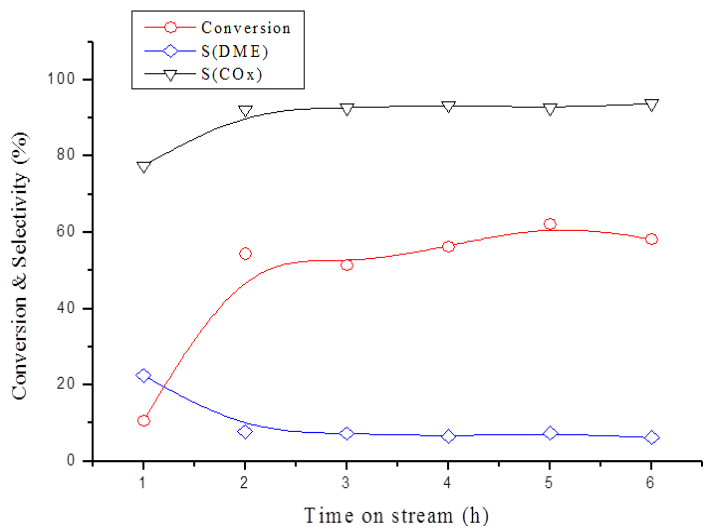

Fig. 9. Dependence of the conversion and product selectivities on time on stream reaction over NiO/CNFs. Reaction conditions: reaction temperature $290^{\circ} \mathrm{C}$; activation temperature $330^{\circ} \mathrm{C}$ under Air for $2 \mathrm{~h}$; volume ratio $\mathrm{Air} / \mathrm{CH}_{3} \mathrm{OH}=2 / 0.5$
In order to see the effect of temperature on the $\mathrm{CH}_{3} \mathrm{OH} / \mathrm{O}_{2}$ reaction, the catalyst sample was activated at $330^{\circ} \mathrm{C}$ and then tested at $250^{\circ} \mathrm{C}$. The results Fig. 10 show a slight decrease in the conversion, which indicates a slight deactivation of the catalyst. On the other hand, a slight decrease in the selectivity of the DME in favor of FM and DMM was observed while the selectivity of $\mathrm{CO}_{2}$ remained almost unchanged. These results are in agreement with those reported in the literature ${ }^{20,21}$ where it has been reported that DMM and MF can be formed from DME. Compared to the results obtained at $290^{\circ} \mathrm{C}$, it can be concluded that MF, DMM which are formed from $\mathrm{CH}_{3} \mathrm{OH}$ or via DME, are converted to $\mathrm{CO}_{2}$ by total oxidation. Taking into account the obtained results, the possible reaction routes of $\mathrm{CO}_{2}$, $\mathrm{DME}$, MF and DMM can be found in scheme 1.

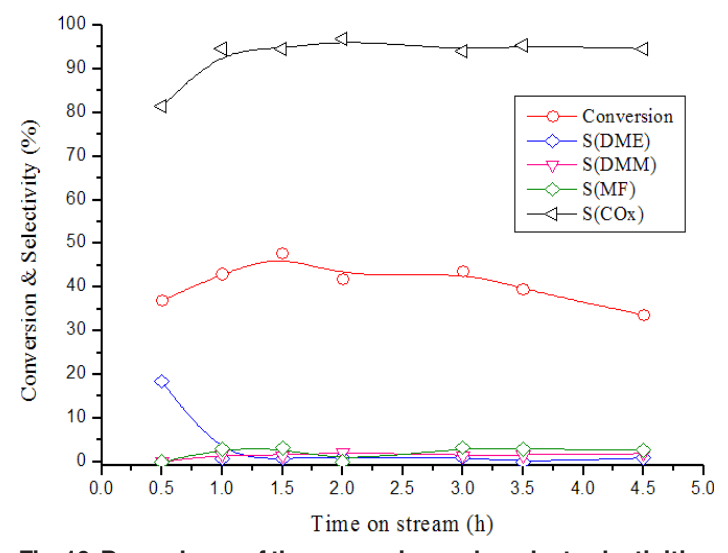

Fig. 10. Dependence of the conversion and product selectivities on time on stream reaction over NiO/CNFs. Reaction conditions: reaction temperature $250^{\circ} \mathrm{C}$; activation temperature $330^{\circ} \mathrm{C}$ under Air for $2 \mathrm{~h}$; volume ratio $\mathrm{Air} / \mathrm{CH}_{3} \mathrm{OH}=2 / 0.5$

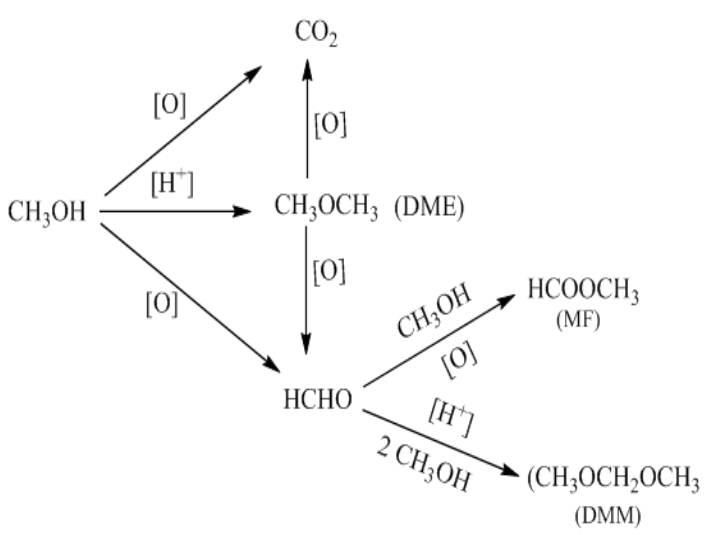

Scheme 1. Proposed methanol reactions pathways on $10 \% \mathrm{NiO} / \mathrm{CNF}$ catalyst 


\section{CONCLUSION}

$\mathrm{NiO}$ nano particles were succefully prepared and loaded on functionalized carbon nanofibers (CNFs). The as-prepared NiO-CNFs material was tested as electrocatalyst and catalyst for the conversion of methanol in gas phase. The results show that the NiO/CNFs catalyst has considerable activities for methanol oxidation. In fact it showed high stability which proofed by repetitive cycles as a result of catalyst surface activation. However, additional studies of both the intermediate $\mathrm{NiO}$ material and the final NiO-CNFs catalyst are recommended for future work. The conversion of methanol in gas phase at $290^{\circ} \mathrm{C}$ over NiO-CNFs catalyst in fresh, reduced, and oxidized forms, led to dimethyl ether (DME) and $\mathrm{CO}_{2}$ as main products. Formaldehyde (FA), methyl formate (MF) and dimethoxymethane (DMM) were observed as traces.

The conversion of methanol alone at $290^{\circ} \mathrm{C}$ over fresh (neither reduced nor oxidized) $\mathrm{NiO}-\mathrm{CNFs}$ catalyst showed a decrease of the selectivity of DME in favor of that of $\mathrm{CO}_{2}$ which suggest that DME reacts with the formed $\mathrm{H}_{2} \mathrm{O}$ to produce $\mathrm{CO}_{2}$.

Reactivation of the catalyst by $\mathrm{H}_{2}$ (reduction) increased the selectivity of DME to the detriment of that of $\mathrm{CO}_{2}$ (partial oxidation), whereas reactivation by air (oxidation) decreased DME selectivity in favor of that of $\mathrm{CO}_{2}$ (total oxidation). Both cases of reactivation increased the conversion of methanol.

Results of methanol conversion at lower reaction temperature $250^{\circ} \mathrm{C}$ showed a decrease of DME selectivity in favor of that of FM and DMM which indicated that DMM and MF can be formed via DME at lower temperature.

\section{ACKNOWLEDGMENT}

This project was supported by King Saud University, Deanship of Scientific Research, College of Science Research Center.

\section{REFERENCES}

1. Jansen, J. C.; Stocker, M.; Karge, H. G.; Weitkamp, J. In: Stöcker, M.; Karge, H. G.; Jansen, J. C.; Weitkamp, J. (Eds.). Advanced Zeolite Sience and Applications-Studies in surface science and catalysis, Elsevier Science B.V., 1994, 85.

2. $\mathrm{Xu}, \mathrm{Q}$. Nanoporous Materials-Synthesis and Applications, CRC Press, Taylor \& Francis Group., 2013.

3. Liu, Y.; Che, R.; Chen, G.; Fan, J.; Sun, Z.; Wu, Z.;Wang, M.; Li, B.; Wei, J.; Wei, Y.; Wang, G.; Guan, G.; Elzatahry, A. A.; Bagabas, A. A.; Al-Enizi, A. M.; Deng, Y.; Peng, H.; Zhao. D. Sci Adv., 2015, 1(4), e1500166.

4. Li, Y.; Luo, W.; Qin, N.; Dong, J.; Wei, J.; Li, W.; Feng, S.; Chen, J.; Xu, J.; Elzatahry, A. A.; Es-Saheb, M. H.; Deng, Y.; Zhao. D. Angew. Chem. Int. Ed., 2014, 53, 9035-9040.

5. Zhang, R.; Shen, D.; Xu, M.; Feng, D.; Li, W.; Zheng, G.; Che, R.; Elzatahry, A. A.; Zhao, D. Adv. Ener. Mater., 2014, 4(8), 1 - 7.

6. Elzatahry, A. A.; Salah El-Din, T. A.; Elsayed, A.; Aldhayan, D. M.; Wadaan, M. A. M.; AlEnizi, A. M.; Al-Deyab, S. S. Sci. Adv. Mater., 2014, 6(7) 1531-1534.

7. Stevens, W. J. J.; Meynen, V.; Bruijn, E.; Lebedev, O. I.; Van Tendeloo, G.; Cool, P.; Vansant, E. F. Microporous Mesoporous Mater., 2008, 110(1), 77-85.

8. Groen, J. C.; Moulijn, J. A. ; Perez-Ramirez, J. J. Mater. Chem., 2006, 16(22), 2121-2131.
9. Salah El-Din, T. A.; Elzatahry, A. A; Aldhayan, D. M.; Al-Enizi, A. M.; Al-Deyab, S. S. Int. J. Electrochem. Sci., 2011, 6, 6177-6183.

10. Al-Enizi, A. M.; Ghanem, M.A.; El-Zatahry, A. A.; Al-Deyab, S. S. Electrochim. Acta., 2014, 137, 774-780

11. Al-Enizi, A. M.; Elzatahry, A. A.; Abdullah, A. M.; AlMaadeed, M. A.; Wang, J.; Zhao, D.; AlDeyab, S. S. Carbon., 2014, 71, 276-283.

12. Treacy, M.M.; Higgins, J.B. Collection of Simulated XRD Powder Patterns for Zeolites, fifth revised ed., Elsevier., 2007.

13. Elzatahry, A. A. Int. J. Electrochem. Sci., 2014, 9, 22-31.

14. Tatibouet, J. M. ; Germain, J. E. ; Volta, J. E. J. Catal., 1983, 82(1), 240-244.

15. Louis, C.; Tatibouet, J. M. ; Che, M. J. Catal., 1988, 109(2), 354-366.

16. Roozeboom, F.; Cordingley, P. D.; Gellings, P. J. J. Catal., 1981, 68(2), 464-472.

17. Wang, X.; Ma, K.; Guo, L.; Tian, Y.; Cheng, Q.; Bai, X. Appl. Catal. A, General., 2017, 540, 37-46.

18. Kim, D.; Park, G.; Choi, B.; Kim, Y-B. Int. J. Hyd. Ener., 2017, 42(49), 29210-29221.

19. Navarro, R. M.; Peña, M. A.; Fierro, J. L. G. J. Catal., 2002, 212(1), 112-118.

20. Zhang, Q. ; Tan, Y. ; Yang, C. ; Han, Y. Catal. Commun., 2008, 9(9), 1916-1919.

21. Liu, G.; Zhang, Q.; Han, Y.; Tsubaki, N.; Tan, Y. Green Chem., 2013, 15, 1501-1504. 